\title{
Realization of breeding values for milk fatty acids in relation to seasonal variation in organic milk
}

\author{
Nina A. Poulsen, ${ }^{1 *} \odot$ Lisa Hein, ${ }^{2}$ Morten Kargo, ${ }^{3} \odot$ and Albert J. Buitenhuis ${ }^{3}$ () \\ ${ }^{1}$ Department of Food Science, Science and Technology, Aarhus University, Blichers Allé 20, PO Box 50, DK-8830 Tjele, Denmark \\ ${ }^{2}$ SEGES, Agro Food Park 15, 8200 Aarhus N, Denmark \\ ${ }^{3}$ Center for Quantitative Genetics and Genomics, Department of Molecular Biology and Genetics, Aarhus University, Blichers Allé 20, PO Box 50, \\ DK-8830 Tjele, Denmark
}

\begin{abstract}
Prediction of detailed milk fatty acid (FA) composition by mid-infrared spectroscopy (MIRS) offers possibilities for high-throughput indirect measurements of detailed milk compositional parameters through the milk testing system, which can be used to differentiate the FA profile by genetics or specific management or on dairies for milk quality evaluation. Since 2015, milk samples from all Danish dairy cows under milk testing have been recorded using MIRS. The MIRS software from the FOSS Application Note 64 was used to predict contents of $7 \mathrm{FA}$ groups and 4 individual FA. Data generated from the application note have been used to estimate breeding values for sires for percentage of saturated fat (SFA\%) in milk. To investigate whether extreme SFA\% breeding values of sires were reflected in the detailed milk FA profile from their daughters, milk samples from 194 cows in 7 organic herds were collected and the detailed FA composition measured by gas chromatography. From each cow, milk samples were collected twice to explore specific seasonal effects of pasture-based diets in relation to sires' estimated breeding value (EBV) for MIRS-predicted SFA\% (MIRS-SFA\%). The results showed a significant difference in SFA\% measured from GC (GC-SFA\%) in milk from daughters of sires having high SFA\% EBV compared with daughters of sires having low SFA\% EBV. The EBV group (low or high) also significantly affected most FA except C13:0, C15:0, C17:0, and C18:1 trans-11. Contents of SFA with even chain-lengths were all higher in the high EBV group, whereas C14:1, C16:1, and the other unsaturated C18 FA had a higher content in the low EBV group. All FA were significantly affected by season. The SFA\% decreased from indoor spring feeding to summer pasture, as did FA with chain length $\leq 16$ carbons, whereas long-chain FA $(>\mathrm{C} 17)$ all increased
\end{abstract}

Received June 4, 2019.

Accepted November 20, 2019.

*Corresponding author: Nina.Poulsen@food.au.dk during summer pasture. The results show that use of MIRS-predicted EBV for SFA\% will most likely display a correlated response on the detailed FA composition in milk. In the current study, the combined action of feeding and genetics resulted in a 10 percentage-point difference on average when comparing milk SFA\% from daughters of high SFA\% EBV sires during indoor spring feeding from one farm to milk SFA\% from daughters of low SFA\% EBV sires during summer from another farm.

Key words: fatty acids, gas chromatography, pasture, mid-infrared spectroscopy

\section{INTRODUCTION}

Milk fatty acid (FA) composition from dairy cows is affected by both genetic and environmental factors. With respect to human nutrition, it is desirable to increase the level of UFA in milk and especially an increase of essential FA, such as linoleic and $\alpha$-linolenic acid, or FA with specific beneficial health effects, such as CLA and n-3 FA, can be of interest (German and Dillard, 2006). Regarding SFA, the effect on human health is still under debate. Instead of focusing on SFA as a whole, negative effects of specific FA in relation to low-density lipoprotein and high-density lipoprotein cholesterol have been central, and a decrease in particularly palmitic acid has been proposed as favorable (Mensink et al., 2003; Givens, 2010). Changing FA composition may also affect product quality because higher levels of UFA can influence texture and flavor of dairy products due to increased softness and higher risk of oxidation (Hurtaud et al., 2002; Couvreur et al., 2006).

Forage-based feeding in particular affects milk FA composition in a favorable manner, increasing the content of beneficial FA including n-3 FA and CLA (Dewhurst et al., 2006; Larsen et al., 2010). Thus, organic milk has generally been perceived as healthier, especially summer milk, when cows are on pasture. In a large study by Benbrook et al. (2013), the concentra- 
tions of n-3 FA ( $\alpha$-linolenic acid, eicosapentaenoic acid, and docosapentaenoic acid) as well as CLA were all higher in organic milk than in conventional milk, where cows stayed indoors all year. The FA composition of organic milk does also vary substantially during the year. Aside from feeding, breed effects on the milk FA composition are pronounced. Jersey cows tend to have higher FA de novo synthesis in the mammary gland and thus higher concentrations of de novo FA in milk compared with Holstein cows (Poulsen et al., 2012). Furthermore, heritabilities for de novo FA are generally higher than for C18 FA, for example, and the genetic potential for changing de novo FA is higher than that for changing $\mathrm{C} 18 \mathrm{FA}$, which are more feed dependent (Krag et al., 2013). In Denmark, regulations require that organic dairy cows have free access to pasture from April to November when climate and animal health allow this. However, within organic management, feed differences may still be pronounced because of different feed practices during indoor feeding and varying concentrate supplementation during summer. Furthermore, increasing prices for imported protein and a tendency toward self-sufficiency have resulted in greater use of alternative protein sources, mainly from legumes in organic production.

Use of mid-infrared spectroscopy (MIRS) for prediction of groups of FA or specific individual FA has enabled high-throughput analysis of milk FA composition through the milk testing system. Hein et al. (2018) used routine screening of milk samples from the Danish dairy cattle population for genetic parameter estimation and documented good potential for changing FA composition in milk through selective breeding. In the current study, we wanted to explore how breeding values for percentage of SFA (SFA\%) are realized in daughters' milk using MIRS and how these values respond to changes in feeding on organic farms from spring indoor feeding to summer pasture with a high amount of fresh grass in a smaller set-up where milk FA composition based on MIRS was supported with detailed FA composition based on GC. This also allowed investigation of correlated effects of breeding for SFA\% on minor milk FA.

\section{MATERIALS AND METHODS}

\section{MIRS Predictions of FA from Routine Herd Testing}

As a part of the regular herd milk testing, where a representative milk sample is collected and sent to the milk testing laboratory, milk samples from each herd were collected and analyzed at a certified laboratory (Eurofins, Vejen, Denmark) by infrared spectroscopy (MilkoScan FT+/FT6000, Foss, Hillerød, Denmark) equipped with a special software (Foss Application Note 64 , Foss), which is able to predict 7 FA fractions: SFA, MUFA, PUFA, short-chain FA, medium-chain FA, long-chain FA, and trans FA, as well as 4 individual FA: C14:0, C16:0, C18:0, and C18:1. Raw MIRS-predicted measurements, provided as grams of FA per 100 g of milk, were stored in the Danish Cattle Database (SEGES, Skejby, Denmark). Furthermore, percentage of test-day FA was defined as the ratio of the content of the FA fraction to the sum of the SFA, PUFA, and MUFA contents. Only MIRS-predicted SFA\% (MIRSSFA\%) was used in the current study.

\section{EBV for SFA\% Based on MIRS FA Predictions}

The EBV used in the analyses were based on milk samples collected during regular herd testing from May 2015 to October 2016 from primiparous Danish Holstein cows participating in the Danish herd testing scheme. After editing as outlined in Hein et al. (2018), 2,135,951 milk samples from 425,558 cows were used for the present breeding value estimation. Including pedigree animals, the data set included $1,118,675$ animals. For estimation of breeding values for milk MIRS-SFA $\%$, the REML approach in DMU (Madsen and Jensen, 2007) based on the following univariate repeatability linear animal model was used:

$$
\mathbf{y}=\mathbf{X b}+\mathbf{Q h}+\mathbf{Z a}+\mathbf{W} \mathbf{p e}+\mathbf{e},
$$

where $\mathbf{y}$ is the vector of test-day observations of SFA content in $\%, \mathbf{b}$ is the vector of fixed effects, $\mathbf{h}$ is the vector of random herd effects, $\mathbf{a}$ is the vector of random animal effects, pe is the vector of permanent environmental effects, e is the vector of residual effects, and $\mathbf{X}, \mathbf{Q}, \mathbf{Z}$, and $\mathbf{W}$ are incidence matrices relating records to fixed, herd, animal, and permanent environmental effects, respectively. Fixed effects included were the month $\times$ year of recording and a fixed regression accounting for the variability in early lactation, determined by fitting a lactation curve with the following function (Wilmink, 1987):

$$
y_{t}=a+b e^{-k t}+c t,
$$

where $y_{t}$ is FA content in \% of the sum of SFA, MUFA, and PUFA at $t$ DIM, and $a, b$, and $c$ are regression coefficients. The parameters jointly describe the curve shape: $a$ sets the amplitude of daily FA content, $b$ is the acceleration in early lactation, $c$ is the linear decline after the peak, and $k$ affects the duration of the acceleration period (fixed at $k=0.05$; Wilmink, 1987). The breeding values were standardized with a mean of 100 and a standard deviation of 10 for an AI bull having 
more than 10 daughters with data in the data set and having an official NTM (Nordic Total merit) index.

\section{Selection of Animals for GC-MIRS FA Testing}

The experimental design aimed to select animals and farms based on as many daughters from as few bulls with high and low EBV for MIRS-SFA\%. Based on this selection criterion for EBV of the sire for MIRS-SFA\%, cows were selected on 7 organic farms (Table 1). These cows were grouped into a group having sires with high EBV for MIRS-SFA\% and a group having sires with low EBV for MIRS-SFA\%, respectively. In total, milk samples from 81 cows were in the low group (average sire EBV for MIRS-SFA\%: 81 and average EBV for total fat: 97) and milk samples from 113 cows were in the high group (average sire EBV for MIRS-SFA\%: 114 and average EBV for total fat: 106). Twenty-eight bulls were represented in the high group, having from 1 to 12 daughters in the sample set; 19 bulls were represented in the low group, having from 1 to 16 daughters in the sample set. These 47 bulls were represented in regular herd testing from May 2015 to October 2016 with 403,268 milk samples from 104,562 cows, and milk MIRS-SFA\% from these cows were correlated with EBV of sires included in the farm data set.

The sampling was repeated twice to have matching samples from each cow during indoor feeding in late spring and from summer pasture collected in June and July 2017. Thus, in total, milk was collected from 194 cows, resulting in 388 samples analyzed for GC-FA composition. The milk sampling was aligned with regular herd testing and represented the milking just before or after the herd test milking. This resulted in a data set of MIRS-predicted SFA\% from the herd test milking that was closely aligned to the milk samples for GC analysis. In addition to FA measurements, information about milk yield, total fat content, calving date, and DIM were extracted from the Danish Cattle Database (SEGES). There was no restriction on DIM for cows to be included in the data set. Average DIM during indoor feeding was $172 \mathrm{~d}$ and during summer pasture $235 \mathrm{~d}$.

\section{FA Analysis by GC}

The morning milk samples for GC were transferred to the laboratory at Department of Food Science, Aarhus University (Tjele, Denmark) directly after milking. After arrival, milk samples were skimmed $(2,643 \times g$, at $4^{\circ} \mathrm{C}$ for $30 \mathrm{~min}$ ) and cream was collected and stored at $-40^{\circ} \mathrm{C}$ until further analysis by GC. All milk samples contained bronopol to prevent microbial growth. Gas chromatography analysis was conducted essentially as described by Larsen et al. (2011). Peak areas for
Table 1. The number of cows selected from each herd, average EBV of the sire for SFA\% based on mid-infrared spectroscopy-predicted SFA\%, and number of sires represented in the high and low groups, respectively, in each herd

\begin{tabular}{llccc}
\hline Herd & Group & $\begin{array}{c}\text { No. of } \\
\text { cows }\end{array}$ & $\begin{array}{c}\text { EBV for } \\
\text { sire SFA\% }\end{array}$ & $\begin{array}{c}\text { No. of } \\
\text { sires }\end{array}$ \\
\hline H1 & High & 14 & 116 & 7 \\
& Low & 15 & 80 & 5 \\
H2 & High & 14 & 114 & 12 \\
& Low & 5 & 87 & 5 \\
H3 & High & 16 & 110 & 11 \\
& Low & 14 & 81 & 9 \\
H4 & High & 15 & 115 & 12 \\
& Low & 9 & 86 & 5 \\
H5 & High & 15 & 113 & 10 \\
& Low & 8 & 83 & 7 \\
H6 & High & 18 & 115 & 8 \\
& Low & 16 & 81 & 7 \\
H7 & High & 21 & 114 & 12 \\
& Low & 14 & 78 & 4 \\
\hline
\end{tabular}

individual FA were calculated after GC separation. Fatty acids were identified and quantified via the use of external standards (Supelco 37 component FAME mix, Supelco Inc., Bellefonte, PA; GLC 469 methyl ester standard, Nu-Chek Prep Inc., Elysian, MN) and expressed as weight proportion of total identified FA. Individual C18:1 trans isomers were not fully separated, and the peak assigned as C18:1 trans-11 was a mixture of trans-10 and trans-11 isomers. In total, 17 individual FA were measured by GC and expressed as grams of FA per kilogram of fat. The trait GC-SFA\% was defined as the sum of all SFA divided by the sum of all FA, whereas MIRS-SFA\% was defined as SFA divided by the sum of SFA, MUFA, and PUFA.

\section{Statistical Analysis}

To test the effect of season and EBV group on the FA of the GC analysis as well as MIRS-SFA\%, the following model was used ( $\mathrm{R}$ version 3.5.1 and the lme4 library; https://cran.r-project.org/web/packages/lme4/ lme4.pdf):

$$
\begin{aligned}
y_{i j k l m n} & =\mu_{i}+\text { parity }_{j}+\text { herd }_{k}+b_{1} \text { DIM }_{l}+b_{2} \times \exp ^{-0.05 \times D I M_{l}} \\
& + \text { season }_{m}+\text { EBVGroup }_{n}+C O W_{l}+e_{i j k l m n},
\end{aligned}
$$

where $y_{i j k l m n}$ are observations on trait $i$ from cow $l$, in parity $j(j=1,2, \ldots, 5)$, herd $k(k=1,2, \ldots, 7)$, season $m(m=1,2)$, and EBV group $n(n=1,2) ; \mu_{i}$ is the fixed mean effect for trait $i$; $b_{1}$ is the regression coefficient for $D I M_{l}$ in trait $i$, which is a covariate describing the effect of days in milk for each cow $l ; b_{2}$ is the regression coefficient for the Wilmink adjustment 
$\left(\exp ^{-0.05 \times D I M_{l}}\right)$ of DIM in trait $i ; C O W_{l}$ is the random effect of $C O W_{i}$; and $e_{i j k l m n}$ is the random residual effect. Significance of least squares means (LSM) between season effect and EBV group was tested using the lmerTest library in $\mathrm{R}$ (http://cran.uib.no/web/ packages/lmerTest/lmerTest.pdf). The $P$-values were adjusted for multiple testing using the Bonferroni correction ( $\mathrm{n}=38$ tests; $\mathrm{R}$ version 5.3.1). A Bonferronicorrected $P$-value $<0.05$ was considered significant. To plot the effect of EBV group on GC-SFA\%, a reduced model [3] excluding EBV group was used, and the residuals from this model were plotted against EBV group. Likewise, to specifically address the herd effect during indoor spring feeding and summer pasture on GC-measured C16:0 and C18:3n-3, a reduced model [3] excluding herd and season was used, and the residuals from this model were plotted for the 7 herds.

\section{RESULTS}

\section{EBV and Milk SFA\% from GC and MIRS}

Figure 1 shows a strong correlation $(\mathrm{r}=0.88)$ between EBV SFA\% for the sires represented in the experiment and average milk MIRS-SFA\% of daughters based on 403,268 milk recordings. Within the low (19 bulls) and high (28 bulls) groups, a fair correlation was observed, $\mathrm{r}=0.59$ and $\mathrm{r}=0.48$, respectively (Figure 1 ). Using the residual from the reduced model [3] excluding EBV group, significant differences in GC-SFA\% $(P<0.001)$ were found in milk from daughters with bulls having high EBV for SFA\% compared with daughters of bulls having low EBV for SFA\% from the 7 organic herds (Figure 2). A significant difference between daughters from high SFA\% EBV sires compared with low SFA\% EBV sires was also found for MIRS-SFA\% as sum of SFA, MUFA, and PUFA $(P<0.001)$. Low SFA $\%$ EBV sires had daughters with lower GC-SFA\% and MIRSSFA $\%$.

\section{Effect of Season and EBV on Milk FA Composition}

Table 2 shows detailed FA composition based on GC analysis of 388 Danish Holstein milk samples from 7 organic herds as well as milk GC-SFA\% and milk MIRSSFA\% as differences in LSM for indoor spring feeding compared with summer pasture and for the high SFA\% EBV group compared with the low SFA\% EBV group. All individual FA were significantly affected by season. Fatty acids with chain length $\leq 16$ all decreased from spring to summer, whereas longer FA $(>\mathrm{C} 17)$ all increased during summer pasture. The GC-SFA\% decreased from spring to summer pasture. Estimated

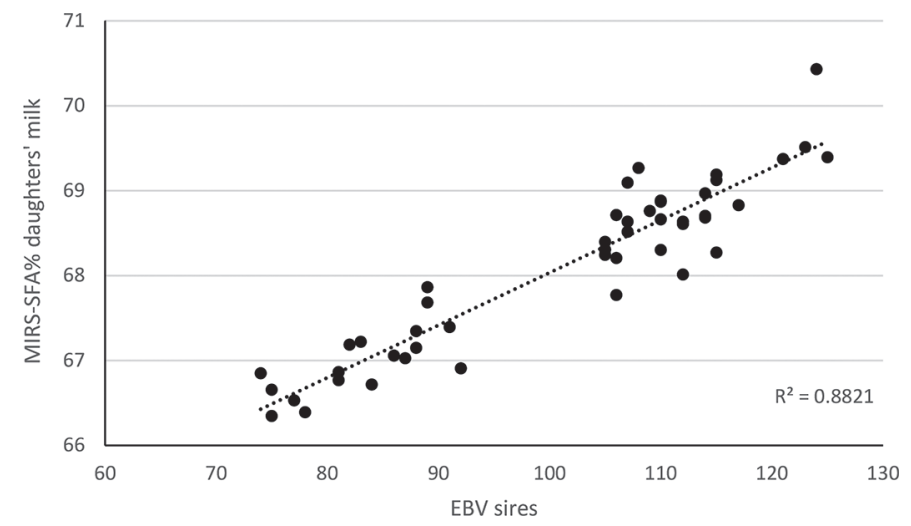

Figure 1. Correlation between EBV for SFA\% for the sires represented in the experiment and average milk mid-infrared spectroscopy predicted SFA\% (MIRS-SFA\%) of all daughters per sire represented in the milk testing, resulting in 403,268 milk recordings $(\mathrm{r}=0.88)$. Correlation coefficients within low and high group were $r=0.59$ and $\mathrm{r}=0.48$, respectively.

breeding value group also significantly affected most FA except C13:0, C15:0, C17:0, and C18:1 trans-11. The SFA with even chain-lengths were all higher in the high EBV group, whereas C14:1, C16:1, and the other unsaturated $\mathrm{C} 18 \mathrm{FA}$ had a higher content in the low EBV group.

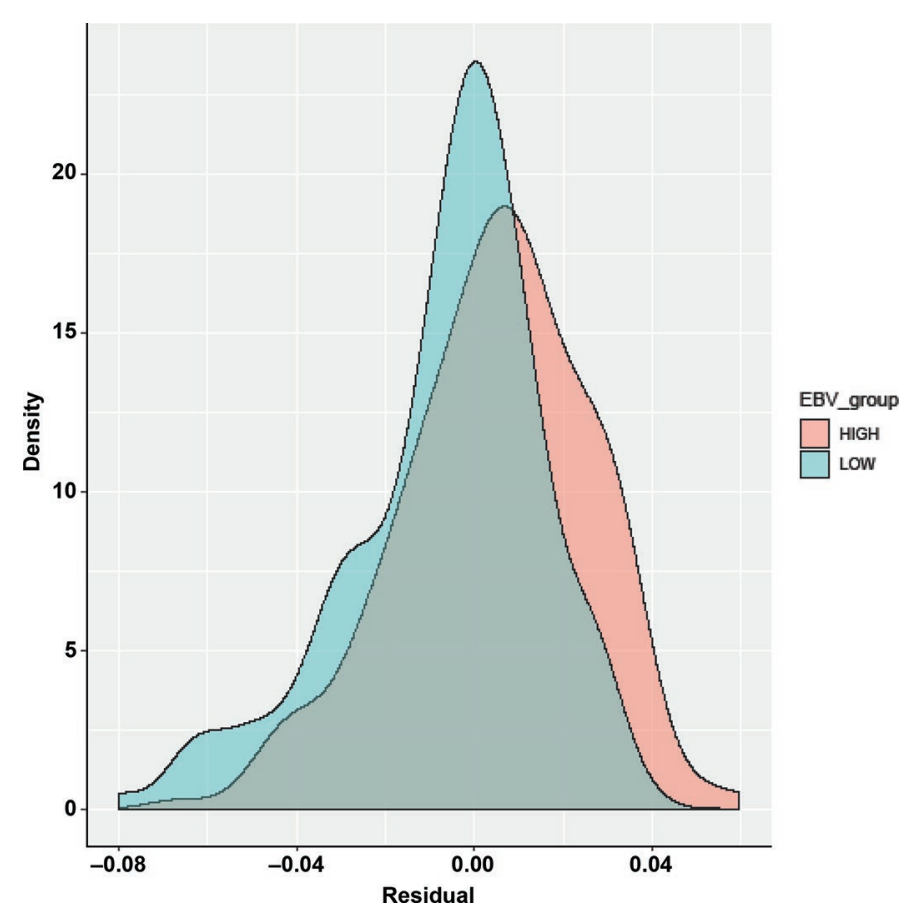

Figure 2. Overlaying frequency distribution for GC-measured SFA\% (GC-SFA\%, based on residuals from the reduced model 3 excluding EBV group) in milk from daughters of sires in the low and high EBV SFA\% group, respectively. 
Distributions of the C16:0 and C18:3n-3 residuals from the reduced model [3] excluding herd and season during indoor feeding in spring and summer pasture for each of the 7 organic herds are shown in Figure 3. As shown in Table 2, C16:0 decreased during pasture feeding compared with indoor spring feeding. During the indoor period, the most striking result was the very high content of C16:0 in herd 4, whereas milk from other herds showed somewhat similar contents of C16:0. From spring indoor feeding to summer pasture, herds 1,3 , and 4 especially displayed large shifts in C16:0, with lower contents during summer pasture. For herds 2 and 6 , the change in feeding did not greatly affect the contents of $\mathrm{C} 16: 0$; during summer pasture, these herds had the highest contents of C16:0. For C18:3n-3, a very clear shift was evident from low contents during indoor feeding to higher contents during summer pasture. Interestingly, the pattern among herds was consistent. On average, C18:3n-3 was increased by $47 \%$, whereas C16:0 decreased $13 \%$ from indoor feeding to summer pasture.

\section{DISCUSSION}

The FA profile of bovine milk is closely linked to the balance of FA in feed, fermentation and biohydrogenation in the rumen, as well as fat mobilization and metabolic processes in the mammary gland. The C4:0 to C14:0 FA are solely generated through de novo synthesis in the mammary gland, whereas varying amounts of C16:0 are synthesized de novo (Grummer, 1991; Sejrsen et al., 2007), where the key regulatory enzymes are acetate CoA carboxylase and FA synthase. Long-chain FA in milk are derived from fat mobilization and feed, but may be modified considerably either through isomerization and hydrogenation in the rumen or through desaturase activity in the mammary gland.

In the current study, only organic farms were included to explore how summer pasture affects milk FA profiles of daughters with high or low SFA\% EBV sires. The results from the MIRS data on these cows confirmed higher MIRS-SFA\% in milk for the high SFA\% EBV group and lower MIRS-SFA\% in milk for the low SFA\% EBV group. This was expected but nevertheless important to ensure that the SFA\% EBV was reflected in the milk from daughters of bulls included in the farm experiment. This was also documented in the small farm data set. Likewise, GC-SFA\% was significantly higher in the high SFA\% EBV group compared with the low SFA\% EBV group, and MIRS-SFA\% and GCSFA\% were highly correlated despite being analyzed in evening and morning milks, respectively. For the specific GC-measured FA, EBV group had a significant effect on all FA except C13:0, C15:0, C17:0, and C18:1 trans-11. The lack of significance for these FA may relate to the size of the data set as well as the somewhat low contents of these FA in milk. However, it could also relate to the origin of these $\mathrm{FA}$, which are linked to rumen bacteria rather than synthesis in the mammary

Table 2. Detailed fatty acid composition ( $\mathrm{g} / \mathrm{kg}$ of fat) and SFA\% measured by GC and predicted by mid-infrared spectroscopy (MIRS) in 388 Danish Holstein milk samples from 7 organic herds presented as LSM differences (spring vs. summer; high vs. low)

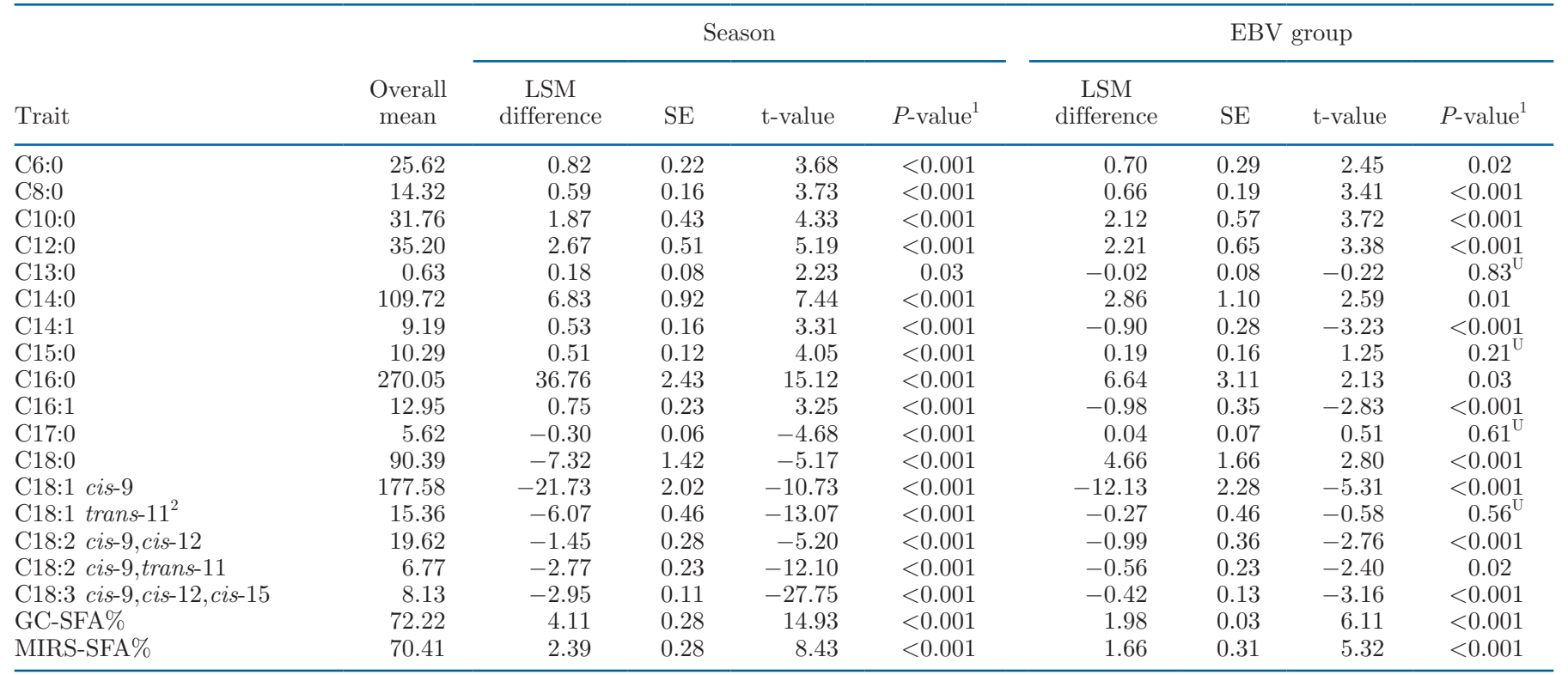

\footnotetext{
${ }^{1}$ Bonferroni-corrected $P<0.05$ unless noted as uncorrected by superscript $\mathrm{U}$.

${ }^{2}$ Individual C18:1 trans isomers were not fully separated and the peak assigned as C18:1 trans-11 is a mixture of C18:1 trans-11 and C18:1
} trans-10. 


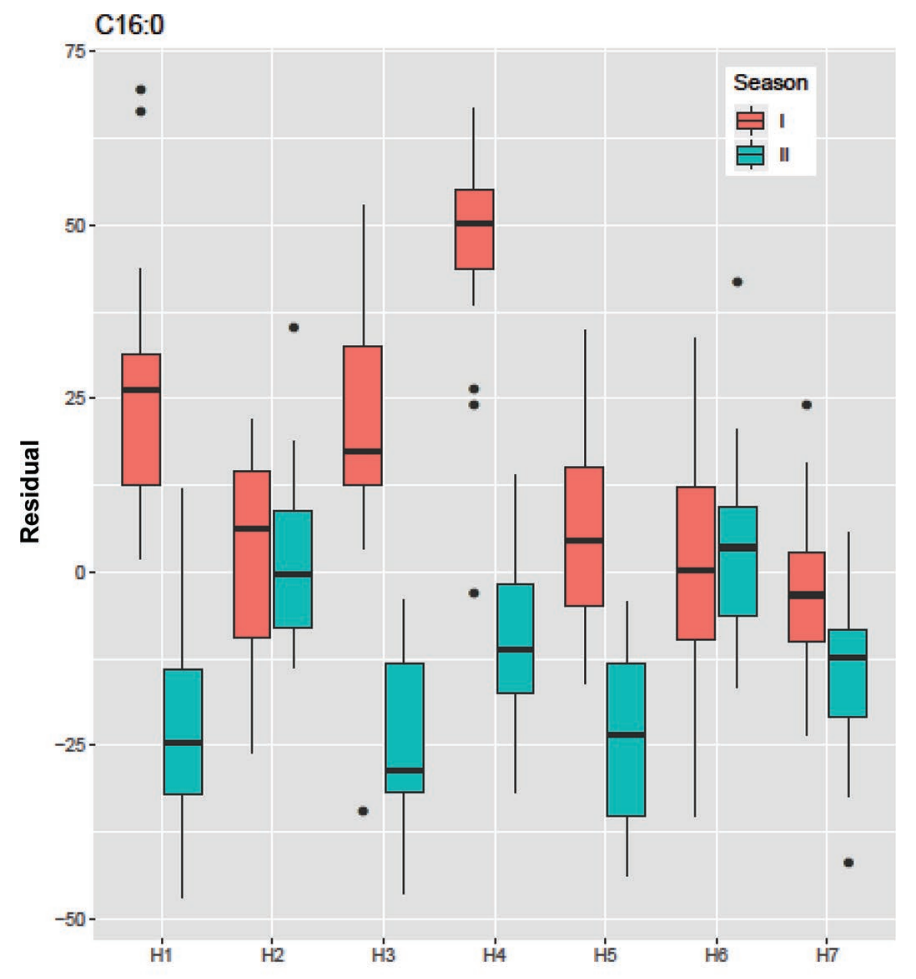

C18:3n3

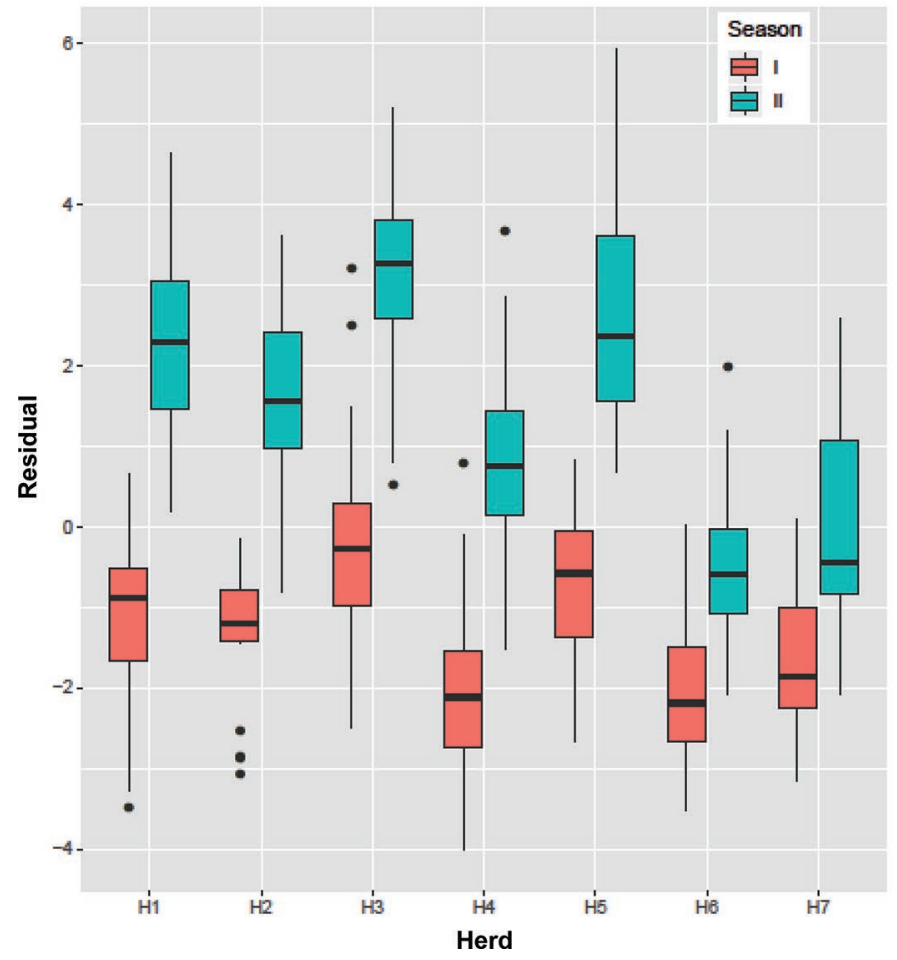

Figure 3. Boxplots of (top) C16:0, and (bottom) C18:3n-3 from GC during spring (season I) and summer pasture (season II) in 7 organic herds (based on residuals from the reduced model 3 excluding herd and season). The boxes highlight the interquantile range of the 25th and 75th percentiles. The horizontal line in the box represents the median, the whiskers represent the minimum and maximum values, and circles represent outliers. gland. The odd-chain FA are largely synthesized de novo by bacteria in the rumen (Vlaeminck et al., 2006). C18:1 trans-11 originates from ruminal biohydrogenation of UFA (e.g., C18:3n-3 and C18:2n-6) and thus is related to feed rich in $\mathrm{C} 18 \mathrm{FA}$. In particular, milk from cows on pasture is high in C18:1 trans-11 compared with milk from cows fed conserved forages (Shingfield et al., 2013).

An earlier study using MIRS data from organic and conventional farms included in the milk testing in Denmark reported significantly lower SFA (but higher short-chain FA) and higher PUFA in milk from organic cows compared with milk from conventional cows, whereas MUFA was not significantly different (Hein et al., 2018). Benbrook et al. (2013) did a large-scale United States-wide study and found that averaged over a full calendar year, organic milk was $4 \%$ higher in SFA and $7 \%$ lower in MUFA; more strikingly, however, C18: 3n-3 and CLA were $60 \%$ and $18 \%$ higher in organic milk, respectively, whereas PUFA and C18:2n-6 were $11 \%$ and $34 \%$ lower, respectively, in organic milk than in conventional milk. Here, MIRS-predicted SFA\% was $72 \%$ in spring and $69 \%$ during summer pasture, which is in line with values reported for organic milk when using 700,000 milk recordings but higher than the average found for Danish Holstein (67.46\%; Hein et al., 2018). Across seasons, there was a $\sim 2$ percentage-point difference in milk MIRS-SFA\% from daughters of low SFA\% EBV sires compared with milk MIRS-SFA\% from daughters of high SFA\% EBV sires. However, when comparing milk SFA\% from daughters of high EBV sires during indoor spring feeding with milk SFA\% from daughters of low EBV group during summer, the difference increased 4 percentage points on average; for the extreme herds, the difference was 10 percentage points, from $66 \%$ for one herd during summer on average in the low group to $76 \%$ for another herd, during indoor spring feeding. This shows that the combined action of genetics and management can change the content of milk SFA\% considerably. Likewise seasonal variation in milk from organic dairy production showed increased MUFA and PUFA during summer and decreased SFA and C16:0 contents (Hein et al., 2018). The data used here confirm these trends but also show that, within organic production, large variation exists during indoor feeding and when cows are on pasture. Summer pasture significantly affected all FA, with a decrease in all mammary gland-derived de novo FA, as well as C13:0, C15:0, C14:1, and C16:1, whereas the contents of C17:0 and all $\mathrm{C} 18 \mathrm{FA}$ increased during pasture. It is well known that grazing decreases de novo FA and C16:0, whereas C18:3n-3 and CLA especially increase during summer pasture (Couvreur et al., 2006; Dewhurst et al., 2006; Larsen et al., 2010). The observed decrease 
in C14:1 and C16:1 during summer pasture is probably a result of the decrease in substrates for desaturation, as these FA mainly relate to desaturase activity in the mammary gland. Around $90 \%$ of $\mathrm{C} 14: 1$ and $55 \%$ of C16:1 derive from the activity of stearoyl-CoA desaturase in the mammary gland (Shingfield et al., 2013). As already stated, C13:0, C15:0, and C17:0 are related to rumen microorganisms, and the current results suggest that pasture feeding leads to a shift toward higher content of C17:0 and lower contents of C13:0 and C15:0.

The current study documented that selection of AI sires based on EBV for SFA\% could be used as a tool to differentiate milk in the direction of less SFA\% (or more UFA\%). However, this selection would be associated with a minor reduction in kilograms of total fat, as AI sires with low EBV for SFA\% also have lower EBV for total fat, as indicated by Hein et al. (2018), who showed a genetic correlation of 0.34 between SFA\% and total fat. The MIRS prediction of groups of FA offers a high-throughput method, which is needed to estimate EBV for these traits. This is a prerequisite for including milk FA in the breeding goal. However, to implement detailed FA profiling routinely in milk testing systems, the FA should be of interest to farmers as a tool in management and breeding. This motivation can be partly delivered by dairies if there is interest in changing the FA profile toward, for example, less SFA\% or specifically less C16:0. The risk factors associated with high dietary intakes of SFA, and particularly C16:0, are still debatable but higher intake of CLA and n-3 FA is favorable; in this respect, pasture-based management plays a positive role and breeding for lower SFA\% will likely lead to an increase of these FA. Heritability estimates for MIRS-based groups of FA or major FA were generally found to be in the same region $(0.07-0.16)$ as heritability for total fat (0.17) in Danish Holstein, when based on single test-day records using more than 700,000 milk recordings (Hein et al., 2018). Although not directly comparable, these heritabilities are somewhat lower than those predicted from GC data of Danish Holstein cows in mid lactation (ranging from $\mathrm{h}^{2}=$ 0.07 for $\mathrm{C} 17: 0$ to 0.34 for $\mathrm{C} 8: 0$ and $\mathrm{C} 10: 0$, respectively; Krag et al., 2013).

In the present study, we included only organic herds instead of comparing conventional with organic farms to demonstrate that organic milk may not be as homogeneous as generally thought. For C16:0, herd 4 had a markedly higher content than the other herds. This farm fed mostly horse beans (Vicia faba), which contain high levels of saturated fat and especially C16:0 compared with other legumes (Grela and Günter, 1995). Horse beans are mainly used as a good protein source and an alternative to imported soybeans and have received interest from organic farmers. The shift and variation observed for $\mathrm{C} 16: 0$ between herds suggest that variation in concentrate supplement during summer pasture strongly affected C16:0 content. As C16:0 is the main SFA thought to have a negative effect on human health due to its association with increasing low-density lipoprotein levels (Givens, 2010), an increase in C16:0 may be undesirable. It is well known that grazing fresh summer pasture has a significant effect on C18:3n-3 content (Butler et al., 2008; Schwendel et al., 2015). Large variation during indoor feeding does, however, indicate that some farms have higher levels of C18:3n -3 during indoor feeding, probably due to feeding grass silage.

\section{CONCLUSIONS}

The study documented how AI bulls with low and high EBV for MIRS-predicted milk SFA\% is reflected in the daughters' SFA content in milk. Furthermore, from a small subset of daughters from 7 organic farms, SFA\% EBV affected most FA except C13:0, C15:0, C17:0, and C18:1 trans-11. Selecting for a healthier FA profile by selection for low SFA\% will thus most likely increase MUFA\% and PUFA\%, together with an increase in C14:1, C16:1, and the other unsaturated C18 FAs. We also documented large changes in FA composition from indoor feeding to summer pasture and showed that milk from organic farms also varies considerably during summer pasture, depending on specific feeding strategies and choice of supplementation during summer pasture.

\section{ACKNOWLEDGMENTS}

The project SOBcows is part of the Organic RDD 2 program, which is coordinated by the International Centre for Research in Organic Food Systems (ICROFS, Tjele, Denmark). This project received grants from the Green Growth and Development Program (GUDP) under the Danish Ministry of Food, Agriculture, and Fisheries (Copenhagen, Denmark). The authors have not stated any conflicts of interest.

\section{REFERENCES}

Benbrook, C. M., G. Butler, M. A. Latif, C. Leifert, and D. R. Davis. 2013. Organic production enhances milk nutritional quality by shifting fatty acid composition: A United States-wide, 18-month study. PLoS One 8:e82429. https://doi.org/10.1371/journal.pone .0082429 .

Butler, G., J. H. Nielsen, T. Slots, C. Seal, M. D. Eyre, R. Sanderson, and C. Leifert. 2008. Fatty acid and fat-soluble antioxidant concentrations in milk from high- and low-input conventional and organic systems: Seasonal variation. J. Sci. Food Agric. 88:14311441. https://doi.org/10.1002/jsfa.3235.

Couvreur, S., C. Hurtaud, C. Lopez, L. Delaby, and J. L. Peyraud. 2006. The linear relationship between the proportion of fresh grass 
in the cow diet, milk fatty acid composition, and butter properties. J. Dairy Sci. 89:1956-1969. https://doi.org/10.3168/jds.S0022 -0302(06)72263-9.

Dewhurst, R. J., K. J. Shingfield, M. R. F. Lee, and N. D. Scollan. 2006. Increasing the concentrations of beneficial polyunsaturated fatty acids in milk produced by dairy cows in high-forage systems. Anim. Feed Sci. Technol. 131:168-206. https://doi.org/10.1016/j .anifeedsci.2006.04.016.

German, J. B., and C. J. Dillard. 2006. Composition, structure and absorption of milk lipids: a source of energy, fat-soluble nutrients and bioactive molecules. Crit. Rev. Food Sci. Nutr. 46:57-92. https:// doi.org/10.1080/10408690590957098.

Givens, D. I. 2010. Milk and meat in our diet: Good or bad for health? Animal 4:1941-1952. https://doi.org/10.1017/S1751731110001503.

Grela, E. R., and K. D. Günter. 1995. Fatty acid composition and tocopherol content of some legume seeds. Anim. Feed Sci. Technol. 52:325-331. https://doi.org/10.1016/0377-8401(94)00733-P.

Grummer, R. R. 1991. Effect of feed on the composition of milk fat. J. Dairy Sci. 74:3244-3257. https://doi.org/10.3168/jds.S0022 -0302(91)78510-X.

Hein, L., L. P. Sørensen, M. Kargo, and A. J. Buitenhuis. 2018. Genetic analysis of predicted fatty acid profiles of milk from Danish Holstein and Danish Jersey cattle populations. J. Dairy Sci. 101:2148-2157. https://doi.org/10.3168/jds.2017-13225.

Hurtaud, C., L. Delaby, and J. L. Peyraud. 2002. Evolution of milk composition and butter properties during the transition between winter-feeding and pasture. Grassl. Sci. Eur. 7:574-575.

Krag, K., N. A. Poulsen, M. K. Larsen, L. B. Larsen, L. L. Janss, and B. Buitenhuis. 2013. Genetic parameters for milk fatty acids in Danish Holstein cattle based on SNP markers using a Bayesian approach. BMC Genet. 14:79. https://doi.org/10.1186/1471-2156 $-14-79$.

Larsen, M. K., J. H. Nielsen, G. Butler, C. Leifert, T. Slots, G. H. Kristiansen, and A. H. Gustafsson. 2010. Milk quality as affected by feeding regimens in a country with climatic variation. J. Dairy Sci. 93:2863-2873. https://doi.org/10.3168/jds.2009-2953.

Larsen, T., M. K. Larsen, and N. C. Friggens. 2011. Enzymatic and fluorometric determination of triacylglycerols in cow milk and other opaque matrices. Food Chem. 125:1110-1115. https://doi.org/ 10.1016/j.foodchem.2010.09.104.
Madsen, P., and J. Jensen. 2007. A user's guide to DMU. A package for analyzing multivariate mixed models. Version 6 , release 4.7. http://dmu.agrsci.dk.

Mensink, R. P., P. L. Zock, A. D. Kester, and M. B. Katan. 2003. Effects of dietary fatty acids and carbohydrates on the ratio of serum total to HDL cholesterol and on serum lipids and apolipoproteins: a meta-analysis of 60 controlled trials. Am. J. Clin. Nutr. 77:1146-1155. https://doi.org/10.1093/ajcn/77.5.1146.

Poulsen, N. A., F. Gustavsson, M. Glantz, M. Paulsson, L. B. Larsen, and M. K. Larsen. 2012. The influence of feed and herd on fatty acid composition in 3 dairy breeds (Danish Holstein, Danish Jersey, and Swedish Red). J. Dairy Sci. 95:6362-6371. https://doi .org/10.3168/jds.2012-5820.

Schwendel, B. H., T. J. Wester, P. C. H. Morel, M. H. Tavendale, C. Deadman, N. M. Shadbolt, and D. E. Otter. 2015. Invited review: Organic and conventionally produced milk-An evaluation of factors influencing milk composition. J. Dairy Sci. 98:721-746. https: //doi.org/10.3168/jds.2014-8389.

Sejrsen, K., T. Bjorn, and S. K. Jensen. 2007. Prospects of obtaining favourable fatty acid composition of cows milk by feeding. J. Anim. Feed Sci. 16(Suppl. 1):7-20. https://doi.org/10.22358/jafs/ $74109 / 2007$.

Shingfield, K. J., M. Bonnet, and N. D. Scollan. 2013. Recent developments in altering the fatty acid composition of ruminant-derived foods. Animal 7(Suppl. 1):132-162. https://doi.org/10.1017/ S1751731112001681.

Vlaeminck, B., V. Fievez, A. R. J. Cabrita, A. J. M. Fonseca, and R. J. Dewhurst. 2006. Factors affecting odd- and branched-chain fatty acids in milk: A review. Anim. Feed Sci. Technol. 131:389-417. https://doi.org/10.1016/j.anifeedsci.2006.06.017.

Wilmink, J. B. M. 1987. Adjustment of test-day milk, fat and protein yield for age, season, and stage of lactation. Livest. Prod. Sci 16:335-348. https://doi.org/10.1016/0301-6226(87)90003-0.

\section{ORCIDS}

Nina A. Poulsen ® https://orcid.org/0000-0001-9983-9663 Morten Kargo (1) https://orcid.org/0000-0003-1981-2722 Albert J. Buitenhuis (으 https://orcid.org/0000-0002-4953-3081 